\title{
Processos de letramento científico-digital: uso de WebQuest na formação inicial de professores
}

\author{
France Fraiha Fraiha-Martins \\ Terezinha Valim Oliver Gonçalves \\ Universidade Federal do Pará
}

\section{Resumo}

Este artigo é parte de uma pesquisa-ação mais ampla, na modalidade narrativa, realizada em um curso da área de Educação em Ciências e Matemática, que forma professores para atuar nos anos iniciais do ensino fundamental, por meio de um desenho curricular interdisciplinar que visa o letramento científico e digital. Objetivamos compreender em que termos os licenciandos significam a utilização de WebQuest em processos de letramento científico-digital. Buscamos apoio em Giordan (2008), Lévy (1993), Sacristán (2002), Moraes, Galiazzy e Ramos (2002), Clandinin e Connelly (2011), dentre outros. Os resultados revelam a potencialidade do uso de WebQuest para a mobilização e construção de conhecimentos científicos e digitais tanto no âmbito da própria aprendizagem ao longo da graduação quanto para a docência nos primeiros anos escolares, associada ao uso de tecnologias digitais.

Palavras-chave: WebQuest, anos iniciais; tecnologias digitais; formação de professores; educação em ciências e matemática.

Scientific-digital literacy processes: use of WebQuest in initial teacher education

\footnotetext{
Abstract

This article is part of a action research, in the narrative modality, carried out in a course in the area of Science and Mathematics Education, which prepares teachers to act in the initial years of elementary education, through an interdisciplinary curriculum design that focuses on scientific
} 
and digital literacy. We aim to understand in what terms the students mean the use of WebQuest in scientific-digital literacy processes. We sought support in Giordan (2008), Lévy (1993), Sacristán (2002), Moraes, Galiazzy and Ramos (2002), Clandinin and Connelly (2011), among others. The results reveal the potential of using WebQuest to mobilize and build scientific and digital knowledge both within the scope of the learning itself during graduation and for teaching in the initial years of elementary education associated with the use of digital technologies.

Keywords: WebQuest; initial years; digital technologies; teacher educacion; science and mathematics education.

\section{Procesos de letramiento científico-digital: uso de WebQuest en la formación inicial de profesores}

\section{Resumen}

Este artículo es parte de una investigación-acción más amplia, en la modalidad narrativa, realizada en un curso del área de Educación en Ciencias y Matemáticas, que forma profesores para actuar en los años iniciales de la enseñanza fundamental, a través de un diseño curricular interdisciplinario que busca el texto científico y digital. Objetivamos comprender en qué términos los licenciandos significan la utilización de WebQuest en procesos de letramiento científico-digital. Buscamos apoyo en Giordan (2008), Levy (1993), Sacristán (2002), Moraes, Galiazzy and Ramos (2002), Clandinin and Connelly (2011), entre otros. Los resultados revelan la potencialidad del uso de WebQuest para la movilización y construcción de conocimientos científicos y digitales tanto en el ámbito del propio aprendizaje a lo largo de la graduación, como para la docencia en los primeros años escolares asociados al uso de las tecnologías digitales.

Palabras clave: WebQuest; años iniciales; tecnologías digitales; formación de profesores; educación matemática y científica.

\section{Introdução}

A cultura de um povo é marcada por suas crenças, valores, maneiras de viver, formas de organização social e, sobretudo, pela forma de pensar e realizar determinadas ações. Os avanços da telemática - associação das telecomunicações à informática - vêm produzindo, neste século XXI, novos instrumentos/ferramentas que passam a ser responsáveis por oferecer novas formas de pen- 
sar e fazer, influenciando diretamente na cultura da sociedade atual (FRAIHA-MARTINS; VIEIRA; GONÇALVES, 2012).

Apropriando-nos do pensamento de Moraes (1997), podemos dizer que a informática e suas associações com outras tecnologias não vem apenas marcando nosso cotidiano com modificações socioeconômicas e culturais, vem também mudando a maneira como pensamos, conhecemos e apreendemos o mundo.

Para Assmann (2000), as novas tecnologias de informação e comunicação já não são meros instrumentos, no sentido técnico e tradicional, mas feixes de propriedades ativas. São algo tecnologicamente novo e diferente. $\mathrm{O}$ autor diz isso porque considera que as novas tecnologias ampliam o potencial cognitivo do indivíduo e possibilitam mixagens cognitivas complexas e cooperativas, na medida em que diversos agentes cognitivos humanos podem interligar-se em um mesmo processo de construção de conhecimentos, estabelecendo parcerias na pesquisa e no aviamento de experiências de aprendizagem.

Nesse sentido, a cultura informatizada, que vem se configurando na sociedade tecnológica em que vivemos, traz como característica constituidora hábitos intelectuais de simbolização, de formalização do conhecimento, de manejo de signos e de representações que utilizam equipamentos computacionais (MORAES, 1997). Assim, para Moraes (1997), passa a existir outro tipo de gestão social do conhecimento, na medida em que usamos um modelo digital que não é lido ou interpretado como um texto clássico, mas "explorado" de forma interativa.

Sendo assim, há que se pensar em processos de formação de (futuros) professores para o exercício da docência sem desconsiderar o tempo presente, marcadamente mediatizado por tecnologias digitais. Isto porque a nova ecologia digital vem provocando novas exigências ao docente, no que se refere ao uso, no cotidiano, de recursos tecnológicos. Dentre elas, o desenvolvimento do letramento

1 Termo utilizado por Green e Bigum (2013). Refere-se ao contexto tecnológico globalizado, melhor explicitado mais a frente. 
digital, que compreende o processo resultante de inúmeras ações de ensinar e aprender a buscar, selecionar, armazenar e sistematizar informações em ambientes digitais e a fazer uso crítico da leitura e da escrita adquiridas nessas ações, em práticas sociais e discursivas desse professor do século XXI, sejam práticas virtualizadas ou não (FRAIHA-MARTINS, 2014).

Do mesmo modo, compreendemos também, como nova exigência no âmbito educacional, o entendimento de não ignorar a urgência de processos formativos que visem ao letramento científico do professor. Para Mamede e Zimmermann (2005), letrar cientificamente o (futuro) professor busca não somente desenvolver a compreensão do conhecimento científico sistematizado, suas condições de produção e utilização, mas possibilitar ao docente a interação crítica com os elementos científicos e tecnológicos da vida social, de modo a torná-lo capaz de intervir, se necessário.

Nós, autoras desta pesquisa, vivemos em um ambiente acadêmico de formação inicial de professores para os anos iniciais de escolaridade, na condição de formadoras e pesquisadoras, desejosas de compreender cada vez mais questões pedagógicas que envolvem processos de letramento científico-digital de futuros professores no âmbito da Educação Matemática e Científica. Isto porque o curso do qual fazemos parte se destina a formar futuros professores dos anos iniciais, por meio de um desenho curricular que intenciona a associação entre a formação específica e a formação pedagógica por meio de práticas interdisciplinares. Além disso, a proposta pedagógica do curso em que atuamos apresenta alguns princípios formativos, tais como: a) a formação fundada em quatro níveis de letramento: linguagem materna, linguagem científica, linguagem matemática e digital; b) a pesquisa como foco no processo de ensino e de aprendizagem; c) a perspectiva metodológica de formação pautada na simetria invertida.

Nesses termos, desenvolvemos, com estudantes da docência deste curso, uma pesquisa-ação envolvendo o ensino por meio de trabalhos coletivos, de uso de tecnologias digitais e de ensino com pesquisa, 
vividos em processos de simetria invertida ${ }^{2}$. Propostas baseadas no entendimento de como o aluno poderá aprender melhor determinado assunto, no tratamento das situações problemáticas do ensino, na cooperação e nos intercâmbios de experiências.

De um lado, importa-nos dizer que não há como ignorarmos o caráter contextual das tecnologias digitais existentes no cenário social e educativo, tampouco a produção de significados e sentidos de valor cognitivo pelo aluno, possibilitada, por exemplo, pelas simulações de fenômenos da natureza por meio do computador (GIORDAN, 2008). Por outro lado, não devemos cair no encantamento ingênuo de que o progresso tecnológico implica necessariamente em avanços da educação. Sacristán (2002, p. 66) enfatiza que, ainda que seja uma tendência irreversível da atividade humana, contra a qual é inútil resistir, "[...] é preciso reconhecer as possibilidades que se abrem, se for o sujeito o controlador do acesso às novas tecnologias e se for este o receptor crítico".

Sob esta perspectiva, compreendemos que é desejável que propostas de formação de professores levem em consideração os aprendizes como sujeitos criativos e críticos, a fim de serem capazes de fazer escolhas adequadas aos seus objetivos educacionais, pois nem tudo o que é tecnologicamente viável é pertinente. E caso seja, não é realizável em todos os contextos. Daí o papel docente de gestor e orientador dos recursos disponíveis, na perspectiva de Sacristán (2002).

Sendo assim, como forma de materializar tais proposições que embasam esta investigação, decidimos lançar mão da metodologia de ensino WebQuest - alunos se envolvem cooperativamente com a realização de uma investigação usando a internet (ABAR; BARBOSA, 2008) - durante o processo formativo desses estudantes em associação à perspectiva teórico-metodológica do ensino com pesquisa, que privilegia o questionamento, a construção de

\footnotetext{
2 O estudante aprende do lugar similar ao que ele vai atuar como docente. Tem que haver coerência entre a formação inicial e o que se espera desse futuro professor.
} 
argumentos e comunicação dos resultados e novas compreensões (MORAES; GALIAZZI; RAMOS, 2002). Portanto, construímos a seguinte questão de pesquisa: Em que termos o uso de WebQuest na formação inicial contribui para o letramento científico-digital de futuros professores dos primeiros anos escolares? Objetivamos compreender em que termos os estudantes significam a utilização de WebQuest em processos de letramento científico-digital.

\section{Percurso metodológico}

Esta pesquisa é parte de uma pesquisa mais ampla ${ }^{3}$. Fazemos a opção por uma pesquisa-ação, de natureza qualitativa, na modalidade narrativa (CLANDININ; CONNELLY, 2011). As ações investigativas foram desenvolvidas por duas professoras formadoras, com licenciandos em dois semestres letivos consecutivos. Tais estudantes pertencem ao curso Licenciatura Integrada em Educação em Ciências, Matemática e Linguagens, que é vinculado à Universidade Federal do Pará. No início da pesquisa, os sujeitos investigados encontravam-se no segundo semestre do curso. Os critérios para seleção dos sujeitos foram: a) participação nos dois semestres formativos de investigação; b) manifestações que contribuem para possíveis respostas à questão de pesquisa. Para este recorte, trazemos quatro sujeitos investigados com nomes fictícios: Dora, Léa, Maria e Sônia.

Em nosso contexto de docência e, ainda, ao interpretarmos as narrativas dos sujeitos imersos nos processos de letramento científico-digital em foco, assumimos epistemológica e metodologicamente autores tais como: Carvalho e Gil-Perez (2006), Chassot (2006), Moraes, Galiazzi e Ramos (2002), Soares (2010), Morin (2004), Pérez-Gomez (1998) e Freire (1996), dentre outros. Os instrumentos investigativos utilizados no âmbito geral da pesquisa foram: questionário, entrevista semiestruturada, diário de campo, registros em áudio e vídeo dos encontros formativos com os estudantes, produções individuais e coletivas no contexto da

Tese de doutorado. 
WebQuest e registros no ambiente virtual Moodle utilizado durante o processo formativo.

Para o tratamento do material empírico produzido, utilizamos a análise textual discursiva, que corresponde a uma metodologia de análise qualitativa (MORAES; GALIAZZI, 2007). Do processo analítico, emergem duas categorias de análise: WebQuest: ferramenta de aprendivagem discente; e WebQuest:ferramenta de ensino para os anos iniciais, das quais trataremos a seguir.

Queremos destacar que o ensino, no contexto desta investigação, foi sistematizado por meio da intencionalidade pedagógica das formadoras (uma das autoras), qual seja: a oferta intencional de tecnologias digitais nos processos de letramento científico subjacente aos planejamentos desenvolvidos durante dois semestres letivos, ora na qualidade de "recurso-meio" para a aprendizagem do futuro docente, ora como "recurso-meio" para o (futuro) ensino. Esta sistematização tem como única intenção facilitar a compreensão da dinâmica de formação desenvolvida.

Embora as qualidades de "recurso-meio" acima mencionadas se interliguem por conectores que expressam alternância (ora aprendizagem, ora ensino), elas não são mutuamente exclusivas. No ir e vir metodológico, ambas se confundem, assumindo uma o significado da outra, assim como propõe a simetria invertida (BRASIL, 2002 , p. 30), posto que os licenciandos, ao utilizarem os recursos digitais em seus processos de aprendizagem, têm a possibilidade de refletir, compreender e aprender sobre o vivido, e de produzir conhecimentos e atitudes docentes.

Apresentamos a seguir um breve relato de uma das professoras formadoras envolvidas, a respeito das ações realizadas, a fim de descrevê-las para melhor entendimento da metodologia do ensino praticado.

Decidimos estudar com os alunos as relações ecológicas de determinadas espécies botânicas, sua importância ambiental, social e comercial nos espaços da EMBRAPA/PA, destacando causas e consequências de um possível desequilíbrio ecológico. Um movimento que seguiria desde o (re) 
conhecimento da espécie, a compreensão das relações ecológicas existentes no ecossistema em que a espécie se encontra, até a discussão de aspectos sociais que envolvem o ambiente. [...]. Conseguimos organizar vários grupos de estudantes com o objetivo de estudar espécies distintas e refletir sobre a diversidade ecológica e aspectos sociais que as envolvem. Pautamo-nos em Moraes, Galiazzi e Ramos (2002) para planejar e executar a atividade investigativa com os estudantes. Queríamos desenvolver pesquisa em aula, utilizando os recursos digitais, dentre eles WebQuest, tendo em vista a orientação investigativa e produção de um espaço educativo propício às práticas interdisciplinares. Antes de ir a campo, criamos coletivamente a questão principal de pesquisa partindo dos componentes curriculares que estavam em foco. Assim, surgiu a seguinte questão de pesquisa: Conhecimento, ensino e proteção ambiental: quais as relações existentes? O que tenho a ver com isso? Para além desta questão mais ampla, orientamos que cada grupo (total de seis grupos), ao entrar em contato com o campo investigado, deveria criar outras questões específicas que norteariam cada contexto de estudo. Já em campo, os grupos desenvolveram três processos: i) coleta de material botânico; ii) caracterização e identificação da espécie; iii) produção de exsicata (amostra de plantas para fins de estudos botânicos). Destaco que, ao longo de todos os processos, estavam disponíveis vários recursos digitais, tais como: filmadora e câmera digitais, gravador de voz, notebook, celular, conexão à internet e Plataforma Moodle (Ambiente Virtual de Aprendizagem gratuito onde estava disponível a WebQuest e espaço para interação entre docentes e alunos).

\section{Webquest: ferramenta de aprendizagem discente}

Compondo a dinâmica metodológica de ensino, consideramos pertinente promover, por meio da tecnologia digital WebQuest ${ }^{4}$, a organização dos estudos e das atividades a serem realizadas e produzidas com os licenciandos. A configuração de um espaço virtual de orientação e interação ao longo dos processos de investigação,

Essa ferramenta proposta por Bernie Dodge consiste em um método educativo para o uso da internet na educação. A proposta nasceu a partir da solução de um problema real em um curso de formação de professores. É como uma missão a cumprir em que grupos de alunos se envolvem cooperativamente com a realização de uma investigação orientada na qual algumas ou todas as informações com as quais os aprendizes interagem são originadas de recursos da internet. 
ao nosso ver, ofereceria aos estudantes aproximações outras com a geografia móvel da informação.

Assim, planejamos o uso de WebQuest durante a formação, assumindo a existência de um espaço virtual que, além de orientar os licenciandos no processo de investigação por meio de desafios e informações, estaria aberto para que eles próprios construíssem este espaço a partir de suas aprendizagens e produções sobre o que estão investigando.

Embora existam vários espaços gratuitos na internet que permitem a construção de WebQuest, decidimos por construí-la no próprio ambiente virtual Moodle, já que era o espaço de interação utilizado por nós durante todo o processo formativo. Assim, produzimos a WebQuest que orientou as ações dos estudantes, com todos seus componentes: introdução, tarefa, processo, recursos, avaliação e produção ${ }^{5}$.

Desejávamos que eles, na condição de estudantes, vivessem a experiência formativa de lançar mão dos recursos de uma WebQuest para estudar e sistematizar seus estudos, de tal forma que pudessem vislumbrar possíveis planejamentos de uso dessa ferramenta com seus futuros alunos.

Diante desse contexto, Dora expressa a experiência vivida na condição de estudante, ao praticar a pesquisa em aula utilizando WebQuest:

O primeiro momento de pesquisa na EMBRAPA foi significativo para o nosso grupo. Conseguimos resolver nossas dificuldades. Realizamos pes-

$5 \quad$ Os componentes da WebQuest compõem uma estrutura semelhante à de projeto educacional. A INTRODUÇÃO é a porta de entrada da WebQuest. Deve apresentar o assunto de modo a convidar e desafiar o participante a seguir no processo de investigação. A TAREFA apresenta os objetivos e evoca ação, o que é para ser feito. O PROCESSO deve orientar claramente a execução das ações. OS RECURSOS apresentam indicações de fontes de informações necessárias ao desenvolvimento da investigação, geralmente na forma de hiperlinks. A AVALIAÇÃO apresenta as formas de avaliação que serão consideradas nas atividades. A PRODUÇÃO é um espaço de postagem das produções, dando visibilidade dos materiais produzidos a todos os participantes. 
quisas na internet, através da WebQuest que estávamos usando. O uso da WebQuest foi revelador, nunca tínhamos utilizado, fomos atrás de material que pudesse nos ajudar, pesquisamos os nomes científicos da espécie botânica em estudo. Nosso grupo interagiu bem com essa tecnologia. (DORA)

Dora não nasceu imersa na ecologia digital (GREEN; BIGUN, 2013). Dora estudou na educação básica em um tempo em que não havia tecnologias digitais disponíveis aos alunos. Essa ecologia foi se formando ao seu redor. Segundo Green e Bigun (2013), os adultos vão se adaptando a essa nova ecologia, uns mais prontamente que outros. Dora indica o não contato cotidiano com as tecnologias digitais, porém demonstra que a interação com essas ferramentas durante o processo formativo vem favorecendo sua aproximação com esses recursos, conforme manifesta: “[...] me ver como professora dos anos iniciais num mundo marcado pelos avanços tecnológicos, eu não me vejo 100\%, mas estou me esforçando para tentar acompanhar". No entanto, Dora revela que o uso da WebQuest contribuiu para o avanço dos "[...] conhecimentos científicos da espécie botânica em estudo".

Segundo Dodge (1995), a WebQuest tem a virtude da simplicidade, portanto, pode ser utilizada tanto por alunos do ensino fundamental quanto por alunos da graduação e pós-graduação. Essa virtude da WebQuest, mencionada por Dodge (1995), contribuiu para que Dora, pouco experiente no uso de tecnologias digitais, pudesse considerar que houve boa interação dela e de seu grupo com essa tecnologia.

Ao planejarmos o uso da WebQuest e demais recursos para a aprendizagem dos licenciandos, tínhamos o propósito de oferecer tecnologias digitais que fossem capazes de promover o habitus discente de lançar mão de recursos dessa natureza para sistematizar e aprender, buscando incorporá-los ao seu meio natural de estudante e futuro docente. Dizemos isso porque compreendemos que, enquanto os recursos digitais não fizerem parte da dinâmica pessoal do licenciando, será pouco provável que ele as incorpore à sua prática docente. Logo, é necessário viver processos de mo- 
bilização de competências na geografia móvel da informação e do conhecimento, a fim de que o futuro professor vislumbre possibilidades docentes utilizando esses recursos (LEVY, 1993). É permitir conhecer a virtualidade da interação social, da leitura, da produção, da comunicação. Propiciar tais processos intenciona desenvolver o letramento digital e científico do futuro professor.

A estudante Léa faz a seguinte consideração:

Esse semestre eu confesso que evoluí muito nos conhecimentos específicos tanto de biologia/ciências, como de linguagem, como da tecnologia. Eu acho que eu cheguei bem perto agora das tecnologias digitais porque eu tinha muita dificuldade.

Léa, ao se referir às aprendizagens desenvolvidas no processo formativo, destaca o avanço na linguagem científica e digital. Léa expressa conhecimentos relativos à espécie Urucum (Bixa orellana L.) e às colmeias das abelhas polinizadoras do urucuzeiro. Quando Léa diz que "[...] a espécie do Urucum é considerada apícola porque as abelhas polinizam a flor do urucuzeiro gerando o fruto" e, ainda, que "[...] é um arbusto de aproximadamente $4 \mathrm{~m}$ de altura, possuindo caule rugoso e tronco com manchas brancas", ela demonstra a apropriação dos conhecimentos biológicos estudados por meio da linguagem científica que manifesta.

Léa também investe na pesquisa sobre o prisma hexagonal reto, como maneira de compreender a geometria das abelhas polinizadoras do Urucum: “[...] o prisma é um sólido geométrico. Sólido são dois planos paralelos, nesse caso, polígonos hexagonais que, quando une todos os pontos de um plano a outro, forma o sólido chamado de prisma hexagonal". Ao finalizar essa narrativa, Léa completa: “[...] então, a WebQuest que usamos para nos orientar nesse processo de pesquisa foi fundamental para encontrarmos essas respostas e avançar nos estudos".

Léa indica em sua narrativa a potencialidade desse recurso digital para a promoção de propostas educativas interdisciplinares, quando utilizada como ferramenta pedagógica para a pesquisa em 
aula. Para Dodge (1995), quanto mais recursos estiverem disponíveis na internet, mais fácil planejar atividades e engajar os aprendizes em investigações ativas e com bom uso do tempo disponível. Dodge (1995) ainda enfatiza que a WebQuest possibilita o trabalho em grupo e promove aspectos motivacionais no aluno para aprender e proporcionar um ambiente de aprendizagem construtivista.

Portanto, a WebQuest permite que o estudante transforme a informação acessada na internet em conhecimento, analisando, comparando, relacionando, julgando e produzindo novas informações. Ademais, desenvolver tais habilidades indica potencialmente o letramento científico-digital dos estudantes da docência envolvidos nesta pesquisa.

\section{Webquest: ferramenta de ensino para os anos iniciais}

Os licenciandos, ao vivenciarem o uso da WebQuest na condição de estudantes, passam a produzir significados sobre o ensino nos anos iniciais utilizando esse recurso digital. Maria diz:

[...] de grande valia foi conhecer ferramentas fundamentais como WebQuest que podem gerar um trabalho diferenciado em uma aula para os anos iniciais, independente da matéria escolar. Isto só fundamenta a ideia de que é possível inovar no ensino básico e contribuir para aprendizagens extraordinárias.

Entendemos que o significado produzido por Maria acerca do uso de tecnologias digitais no ensino tem a ver com a tomada de consciência dos processos de letramento científico-digital vividos na sua formação docente. Considera ferramenta fundamental, ao tempo em que se preocupa com sua formação pedagógica, específica, e com o uso variado de materiais.

Quando Maria se refere ao conhecimento de ferramentas que podem gerar um trabalho diferenciado, ela se remete à aprendizagem que desenvolveu a respeito de associar mais de um recurso computacional na elaboração de atividades docentes, como narra: 
Eu não conseguia ver associação. Como que o ensino dos seres vivos e o meio ambiente vão se unir à tecnologia? Depois, com o andamento do trabalho, foi que eu vi onde esses recursos poderiam se encontrar no ensino de seres vivos e quais as maneiras de eu utilizar. [...]. Podemos associar o uso de WebQuest com a produção de vídeos ou história em quadrinhos.

Maria produz significado para o uso das tecnologias digitais, levando em conta a compreensão do todo formativo vivido, assim como o significado produzido parece estar carregado de sentidos motivacionais experimentados por ela nesse contexto. Maria indica ter produzido significado para o uso dessas tecnologias no ensino, o que passa a configurar sua formação básica para a docência.

A respeito da potencialidade das tecnologias digitais, em consonância com Moran (2000), Moraes (1997) e Assmann (2000), o estímulo à aprendizagem ocorre pelo fato de a multimídia digital operar diretamente com o sensível e o concreto, principalmente as imagens em movimento, pois elas permitem explorar a maioria dos sentidos. Combinam a dimensão espacial com a sinestésica, onde o ritmo torna-se cada vez mais alucinante e motivante na medida em que vai ocorrendo a interatividade com o usuário.

Decorre daí a proposição de que, para jovens e crianças que já nasceram na era da informação, o livro se torna uma opção inicial menos atraente, já que esta mídia acaba competindo com outras mais próximas da sensibilidade deles (multimídias), das suas formas mais imediatas de compreensão. É possível considerar também que a motivação deriva do envolvimento ativo do educando no processo de aprendizagem que pode ser favorecido pela multimídia computacional, pois ela permite a atitude exploratória do aprendiz pela característica reticular e não linear que possui (LÉVY, 1993).

Nesses termos, as proposições acima concorrem para dizermos que os licenciandos, quando ensaiam planejamentos de ensino que requerem a utilização de WebQuest, inserem-se em uma perspectiva favorável ao processo de ensino e aprendizagem qualitativamente positivo do ponto de vista motivacional, pelo caráter interativo e autoral que os licenciandos atribuem às propostas, 
fundamentalmente, em suas últimas produções de planejamento de ensino.

Compreendemos que desenvolver processos de letramento científico-digital ao longo da formação inicial de professores para os anos iniciais - em vários momentos durante o curso - poderá permitir espaços e tempos para a produção de significados em relação ao uso de tecnologias digitais no ensino, para além do que os discursos sociais expressam.

Espaços para experimentar diversas tecnologias digitais, em diversas propostas pedagógicas, contemplando diversos componentes curriculares. E tempos que possam respeitar o ritmo de cada licenciando no processo de aquisição de um estado ou condição de autoria docente que envolva o uso de tecnologias digitais em processos de ensino.

A proposta de uso da WebQuest - As SuperFrutas com alunos do $5^{\circ}$ ano, produzida por Sônia e seu subgrupo, indica favorecer a interatividade digital e autoria discente, a começar das possibilidades que se abrem quando os alunos passam a desenvolver uma pesquisa orientada a partir do uso da internet. Ao socializar o planejamento de uso da WebQuest construída, Sônia expressa:

[...] na introdução da WebQuest convidamos as crianças a pesquisarem sobre os benefícios medicinais das frutas. Relacionamos os super-heróis às super-frutas. Colocamos imagens que motivassem as crianças: a banana vestida de Thor, a maça de homem de ferro, o coco de lanterna verde. [...]. Dentre dez frutas que disponibilizamos na ferramenta Tarefas (maracujá, caju, laranja da terra, goiaba, murici, noni, acerola, cacau, jambo e manga), cada grupo deverá pesquisar sobre uma delas, saber em qual ambiente ela se adapta e se há algum lugar na escola que o grupo poderá plantá-la. [...]. As crianças deverão ficar atentas durante as apresentações dos grupos, pois as informações socializadas serão importantes para que em outro momento os grupos se reagrupem, a partir de características em comum das frutas estudadas. Depois de reagrupados, eles irão produzir na prática um mix de frutas saudáveis para que o suco fique mais nutritivo. $\mathrm{Na}$ atividade de mix de sucos, as sobras das frutas (cascas, sementes, etc.) usadas para fazer o mix, servirão de adubo na realização do plantio frutífero. É possível nesse momento a professora abordar o processo de composta- 
gem, mas é na execução do planejamento que a professora perceberá se será possível ou não. [...]. Ao final, os grupos deverão plantar mudas das frutas estudadas em espaço a ser definido na escola.

Sônia e seu grupo, ao produzirem a WebQuest parcialmente descrita acima, idealizam uma prática de ensino estruturada de forma que os alunos se envolvam no desenvolvimento de uma tarefa de investigação usando principalmente os recursos da internet. Em sua explicitação, Sônia indica ter conseguido organizar a WebQuest - e suas ferramentas Introdução, Tarefas, Processo, Avaliação - a fim de que esse ambiente virtual de aprendizagem orientasse alunos no desenvolvimento de um trabalho de pesquisa sobre os benefícios das frutas e as relações com a alimentação saudável.

É possível inferir que Sônia e seu grupo, ao proporem o uso de WebQuest em seus planejamentos, indicam repercussão da simetria invertida, uma vez que eles vivenciaram os processos de letramento científico-digital apoiados por uma WebQuest elaborada pelas formadoras. E, nesse processo formativo, vários foram os discursos sobre o ensino envolvendo esta tecnologia digital.

Dentre eles, falávamos que não basta dizer aos alunos dos anos iniciais: "pesquisem na internet". É preciso planejar um bom uso da Web. E as orientações para o bom uso dentro de um planejamento específico de ensino podem estar contidas no ciberespaço, na WebQuest. Isso não exime o (futuro) professor de interagir e mediar o processo de ensino e aprendizagem ao longo da execução do planejamento em que a WebQuest está integrada.

Também dizíamos que elaborar uma WebQuest e utilizá-la no ensino dos anos iniciais é uma forma de usar os atrativos da Web para incentivar os alunos a construírem conhecimentos consistentes e significativos. Isto porque, além do potencial de controle da atividade por parte do aluno, a WebQuest, por se constituir no ciberespaço, insere-se em uma realidade tecnologicamente mediada, da qual o aluno faz parte, capaz de tornar-se um ambiente motivacional para a aprendizagem. 
Portanto, compreendemos que a produção de Sônia, que integra o uso da WebQuest ao assunto alimentação saudável, indica o desenvolvimento do letramento científico-digital da licencianda, bem como uma perspectiva interativa e autoral do ensaio de práticas diferenciadas de ensino. As tarefas propostas, a organização da atividade e a dinâmica do trabalho, sistematizadas nesse ambiente virtual por Sônia e equipe, orientam os alunos à busca, à seleção e ao tratamento das informações pertinentes ao estudo, bem como à realidade social em que a temática se insere.

\section{Algumas considerações}

Experiências formativas como a que trouxemos em evidência nesta pesquisa têm sido perseguidas por nós, docentes desse curso, a fim de materializar a proposta curricular de formação que é orientada pela integração de saberes, em especial, o desenvolvimento da linguagem digital de futuros professores que atuarão nos anos iniciais do ensino fundamental, no tempo em que as tecnologias digitais constituem os meios comunicacionais atuais.

$\mathrm{Na}$ realização dos processos de letramento científico-digital, desenvolvemos um design de formação que está alicerçado na tríade formativa: trabalho coletivo, uso de tecnologias digitais, ensino com pesquisa. É possível inferir que o uso da WebQuest nessa atmosfera formativa se constituiu um instrumento de mediação pedagógica capaz de estimular e orientar os estudantes nas pesquisas propiciadas pelas ações das professoras formadoras, ampliando o repertório de experiências educativas que envolvem o uso de tecnologias digitais por futuros professores.

Por um lado, os estudantes manifestam a potencialidade da WebQuest em proporcionar a mobilização e construção de conhecimentos científicos e digitais para o desenvolvimento da própria aprendizagem na condição de alunos. Por outro, o uso da WebQuest nesse espaço formativo propiciou conjecturas e intenções de planejamento de ensino para os anos iniciais do ensino fundamental utilizando esse recurso; ou seja, construíram ideias sobre a docência, com a visão de (futuros) professores. 
Portanto, o uso de WebQuest torna-se uma perspectiva favorável ao processo de ensino e aprendizagem do ponto de vista motivacional, pelo caráter interativo e autoral que propicia aos participantes envolvidos. Consideramos necessária a vivência de futuros professores em processos formativos que privilegiam o uso de tecnologias digitais dessa natureza, a fim de aproximar as práticas docentes das realidades cotidianas dos alunos dos anos iniciais, imersos em um cenário educativo do século XXI, marcado pela complexidade, imprevisibilidade e interconectividade.

\section{Referências}

ABAR, C. A. A.; BARBOSA, L. M. Webquest: um desafio para o professor! São Paulo: Avercamp, 2008.

ASSMANN, H. A metamorfose do aprender na sociedade da informação. Revista Ciência da Informação, Brasília, v. 29, n. 2, maio/ago. 2000.

BRASIL. Ministério da Educação. Diretrizes Curriculares Nacionais para a Formação de Professores da Educação Básica, em nível superior, curso de licenciatura, de graduação plena. Brasília, DF, 2002.

CARVALHO, A. M. P.; GIL-PÉREZ, D. Formação de professores de ciências: tendências e inovações. 8. ed. São Paulo: Cortez, 2006. (Questões da Nossa Época, v. 26).

CHASSOT, A. Alfabetização científica: questões e desafios para a educação. 4 . ed. Ijuí: Ed. Unijuí, 2006. (Educação em química).

CLANDININ, F. M.; CONNELLY, J. Pesquisa narrativa: experiência e história em pesquisa qualitativa. Uberlândia: EDUFU, 2011.

DODGE, B. WebQuests: A Technique for Internet: Based Learning. Tradução de Jarbas Novelino Barato. The Distance Educator, v. 1, n. 2, 1995. Disponível em: <http://www.dm.ufscar.br/ jpiton/downloads/artigo_webquest_original_1996_ptbr.pdf>. Acesso em: 13 fev. 2018.

FRAIHA-MARTINS, F. Significação do Ensino de Ciências e Matemática em Processos de Letramento Científico-Digital. 2014. 189 f. Tese (Doutorado em Educação em Ciências e Matemáticas) - Instituto de Educação Matemática e Científica, Universidade Federal do Pará, Belém, 2014. 
FRAIHA-MARTINS, F.; VIEIRA, E. P. P.; GONÇALVES, T. V. O. Redes de informação e inteligência coletiva: bases epistemológicas para pensar a educação matemática e científica. Alexandria: Revista de Educação em Ciência e Tecnologia, Florianópolis, v. 5, n. 2, p. 209-227, set. 2012.

FREIRE, P. Pedagogia da Autonomia: Saberes necessários à prática educativa. 33. ed. São Paulo: Paz e Terra, 1996. (Leitura).

GIORDAN, M. Computadores e linguagens nas aulas de ciências: uma perspectiva sociocultural para compreender a construção de significados. Ijuí: Ed. Unijuí, 2008. (Educação em Ciências).

GREEN, B.; BIGUM, C. Alienígenas na sala de aula. In: SILVA, T. T. (Org.). Alienígenas na sala de aula: uma introdução aos estudos culturais em educação. Petrópolis: Vozes, 2013. p. 203-237.

LÉVY, P. As tecnologias da inteligência: o futuro do pensamento na era da informática. São Paulo: Editora 34, 1993.

MAMEDE, M. ZIMMERMANN, E. Letramento Científico e CTS na formação de professores para o ensino de ciências. Enseñanza De Las Ciencias, 2005. número extra. VII CONGRESO. Acesso em 15/02/2013.

MORAES, M. C. O paradigma educacional emergente. 10. ed. Campinas: Papirus, 1997.

MORAES, R.; GALIAZZI, M. C. Análise textual discursiva. Ijuí: Ed. Unijuí, 2007.

MORAES, R.; GALIAZZI, M. C.; RAMOS, M. G. Pesquisa em sala de aula: fundamentos e pressupostos. In: MORAES, R.; LIMA, V. M. R. (Org.). Pesquisa em sala de aula: tendências para a educação em novos tempos. Porto Alegre: EDIPUCRS, 2002. p. 25-49.

MORAN, J. M. et al. Novas tecnologias e mediação pedagógica. 6. ed. Campinas: Papirus, 2000.

MORIN, E. A cabeça bem-feita: repensar a reforma, reformar o pensamento. 10. ed. Rio de Janeiro: Bertrand Brasil, 2004.

PÉREZ-GOMEZ, A. I. Ensino para a compreensão. In: SACRISTÁN, J. G.; PÉREZ-GOMEZ, A. I. Compreender e transformar o ensino. 4. ed. Porto Alegre: Artmed, 1998. p. 67-97. 
SACRISTÁN, J. G. Educar e conviver na cultura global: as exigências da cidadania. Porto Alegre: Artmed, 2002.

SOARES, Magda. Alfabetização e letramento. São Paulo: Contexto, 2010.

\section{France Fraiha Fraiha-Martins}

Universidade Federal do Pará

Professora Doutora do Instituto de Educação Matemática e Científica (IEMCI) da Universidade Federal do Pará (UFPA). Atuo na graduação e pós-graduação no âmbito da Educação Matemática e Científica, dedicando pesquisas à formação de professores e uso de tecnologias digitais no ensino.

francefraiha@yahoo.com.br

\section{Terezinha Valim Oliver Gonçalves}

Universidade Federal do Pará

Profa. Dra. Titular do Instituto de Educação Matemática e Científica (IEMCI), daUniversidade Federal do Pará (UFPA). Pesquisadora na área de Educação em Ciências e Educação Ambiental, atuando principalmente nas linhas de pesquisa: formação de professores, ensino de ciências, formação inicial, pesquisa narrativa e ensino com pesquisa.

tevalim@yahoo.com.br

Submetido em: 25-3-2018

Aceito em: 10-5-2018 